\title{
Coke Engineering. An Update
}

\section{Short Communication}

Volume 2 Issue 1- 2021

\author{
Author Details \\ Fathi Habashi* \\ Department of Mining, Metallurgical, and Materials Engineering, Laval University, Quebec City, Canada \\ *Corresponding author
}

Fathi Habashi, Department of Mining, Metallurgical, and Materials Engineering, Laval University, Quebec City, Canada

Article History

Received: January 07, 2020 Accepted: January 22, 2021 Published: January 25, 2021

\section{Short Communication}

\section{Coke in the blast furnace}

It is said that organic chemistry is the chemistry of carbon while metallurgy is the technology of carbon. Carbon in form of coal is used in metallurgy as a fuel but the major use is to make coke that is an essential component of the feed to iron blast furnaces. For each ton of iron produced, half a ton of coke is used (Figure 1). It is estimated that 639 million short tonnes of coke were produced in 2018 worldwide.

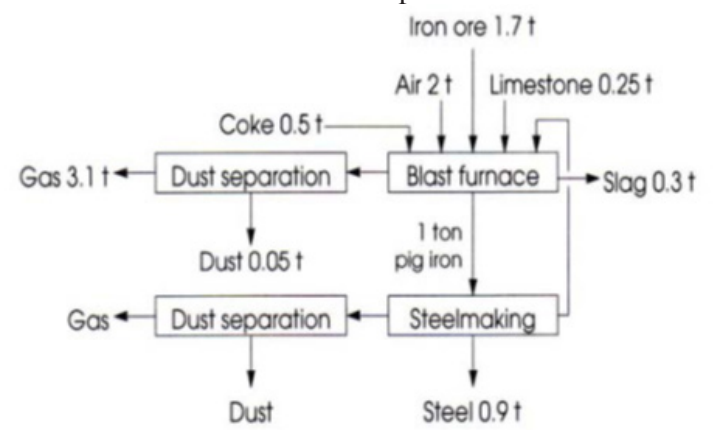

Figure 1: Coke is the basis of the steel industry.

\section{Destructive distillation of coal}

Metallurgy is conveniently divided into ferrous and nonferrous. The production in ferrous metallurgy is at least fifty time the production of all nonferrous metals combined. That is why the ferrous sector is of great importance. The present technology for its manufacture is based on heating coal in retorts in absence of air then quenching the product with a limited supply of water shower (Figures 2-4). The destructive distillation of coal produces coal tar and many chemicals and finally, after purification, the fuel for heating the retorts. Some of the chemicals produced are: aqueous ammonia by scrubbing with water and hydrogen sulfide by sorption - desorption process then production of elemental sulfur in a Klaus kiln (Figure 5), while the distillation of coal tar produces benzene, toluene, naphthalene, anthracene, etc.
The sorption - desorption process is based on absorption of $\mathrm{H}_{2} \mathrm{~S}$ by triethanolamine and desorption by steam. Pitch is also produced as a final product of coal tar distillation. It can be seen that the destructive distillation of coal is a huge process that produces many chemicals.

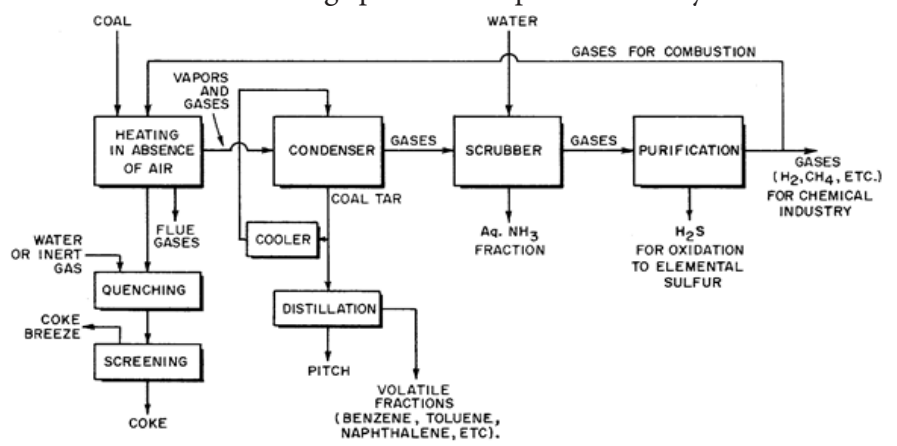

Figure 2: Production of coke from coal.
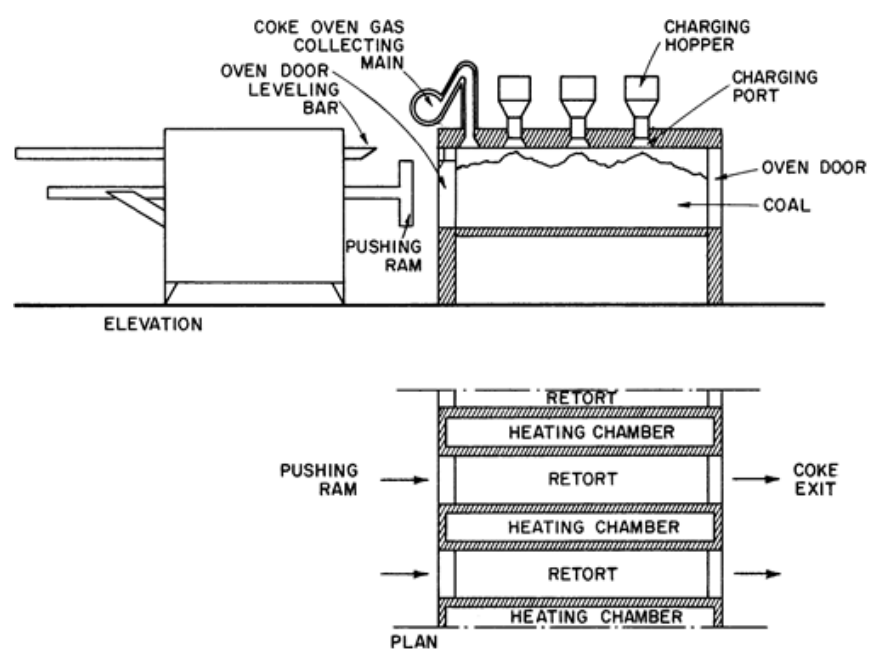

Figure 3: Production of coke in retorts. 


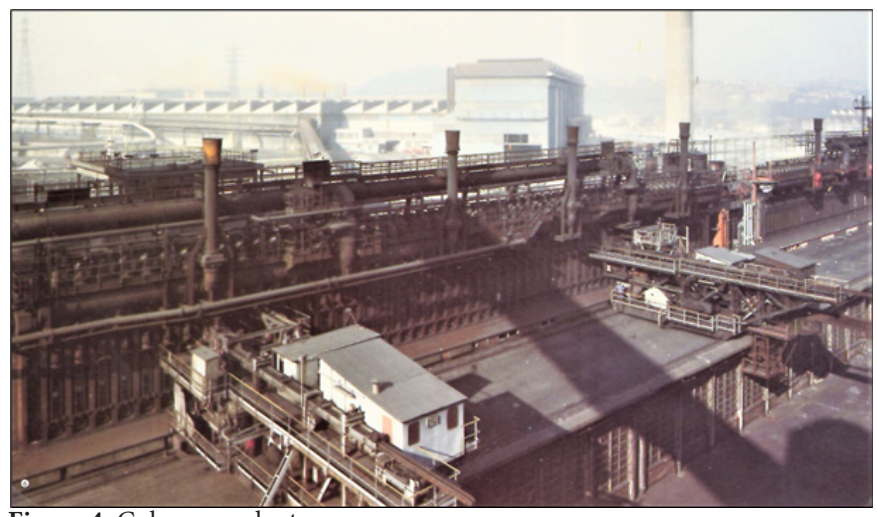

Figure 4: Coke oven plant.

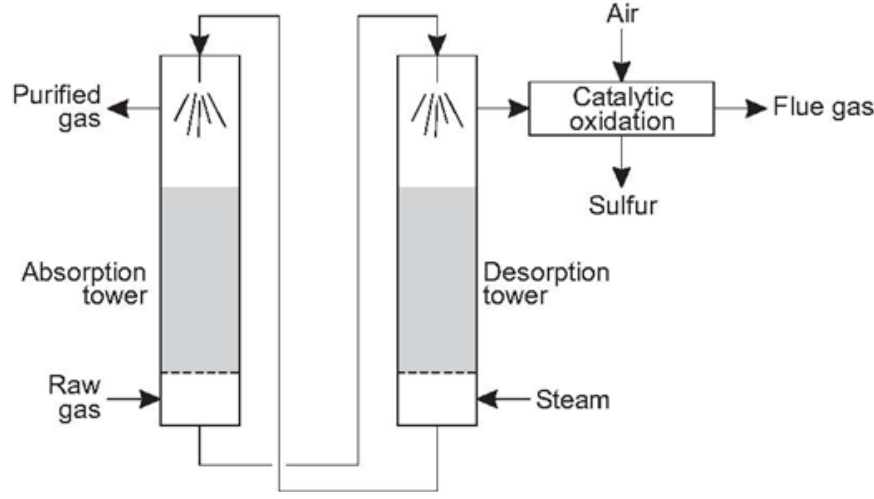

Figure 5: Sorption in triethanolamine and desorption by steam for recovery of hydrogen sulfide followed by catalytic oxidation for converting $\mathrm{H} 2 \mathrm{~S}$ to elemental sulfur.

Quenching with water is highly polluting due to dust and toxic organic emissions (Figure 6). It also consumes appreciable amounts of water.

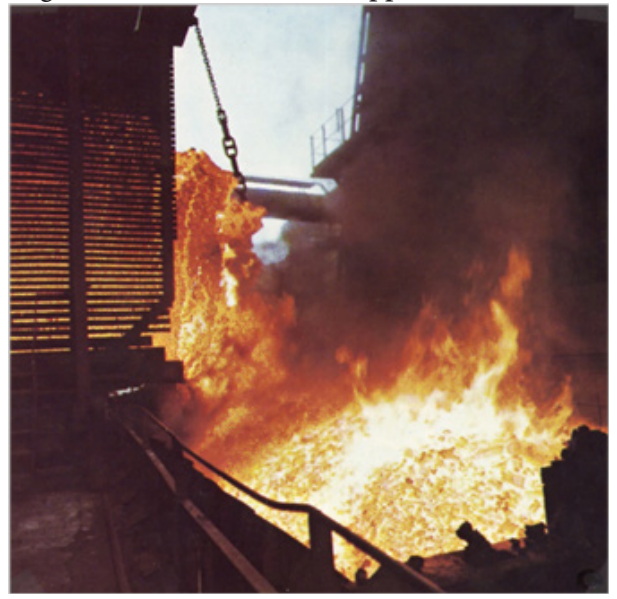

Figure 6: Water quenching of coke.

\section{Dry quenching}

A technology now used in Japan and at a few plants in Korea and China, known as dry quenching, uses nitrogen in a closed circuit to avoid environmental emissions. In addition, heat is recovered in the form of steam, from the red-hot coke. The technology was first introduced by Nippon Steel Corporation at Kitakyushu in 1976. By 2001 ninety percent of coke production in Japan uses this technology and plans are under way to make it to $100 \%$. The use of this technology is widespread in Asia, Europe, and Brazil - - but not yet in North America.

In this process (Figure 7), coke leaving the retorts is charged at the top of a closed reactor that acts as a heat exchanger through which nitrogen at $130^{\circ} \mathrm{C}$ is introduced at the bottom. The coke is then discharged at $200^{\circ} \mathrm{C}$ while nitrogen after passing through a dust removal system leaves at $900^{\circ} \mathrm{C}$ to a boiler to generate steam, and then recycled to quench the coke. In addition to eliminating the pollution in the coke plant and recovering the heat from the hot coke, less coke fines are produced [1-3].

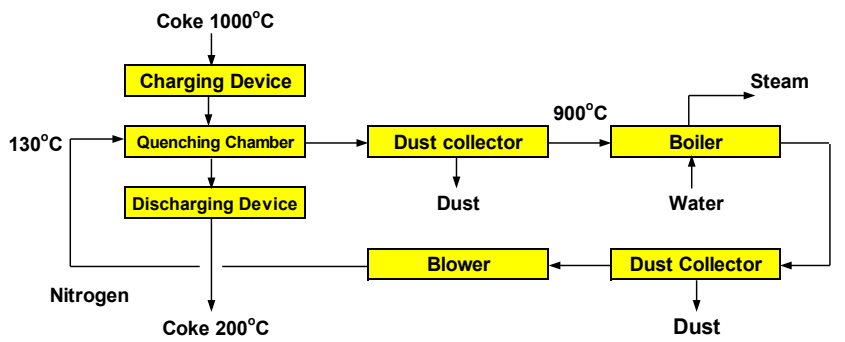

Figure 7: Dry quenching plant of coke.

It is evident that in an integrated steel plant, air is liquefied to produce oxygen for top-and-bottom blowing technology. Nitrogen generated in this operation could be recovered for the Dry Quenching process. Dry quenched coke is harder and stronger, and its moisture content is much lower than that of wet quenched coke. Furthermore, water is not wasted from the process and not contaminated with toxic pollutants. In North America dry quenching has been repeatedly rejected as unnecessary and costly

\section{Summary}

In summary the production of coke from coal involves the production of many chemicals. Coke is produced in tremendous amounts to satisfy the needs of the blast furnace for iron production. The new technology of dry quenching of coke first introduced by Nippon Steel Corporation at Kitakyushu in Japan in 1976 is now used at a number of plants in other countries. It uses nitrogen in a closed circuit to avoid environmental emissions. In addition, heat is recovered in the form of steam, from the red-hot coke. In steel plants oxygen is used extensively and therefore by-product nitrogen from air liquefaction can be effectively utilized in this way.

\section{References}

1. Y Ishida, K Yokote (2001) Coke Dry Quenching in Connection with Environmental Counter Measures and Energy Savings, p. 21-26

2. www.zone.ul.ca

3. F Habashi (2014) Clean Technology in Coke Production, Proceedings Conference of Metallurgists, Canadian Institute of Mining, Metallurgy, and Petroleum, Montreal. 